\title{
General Discussion to Papers of D. Abrahams et al. read by Dr Shrosbree
}

Dr Dollfus (Chairman). I would like to ask you what you mean by early stage when you sit them up with your collar?

Dr Shrosbres ( $S$. Africa). We try to get the patient up in 8 to ro weeks' time as opposed to 12 weeks. Previously we were very conservative in our treatment.

DR Dollfus. Eight weeks?

Dr SHROSBREE. Eight to Io weeks.

DR Dollfus. Eight to Io weeks. I would like to add a few words on what you said of selecting patients. Is this selecting patients for surgery? As you know there is a tendency, especially in the United States and Canada, to operate these patients immediately as well as later and do all sorts of things to them and especially one operation which is supposed to be successful of which I haven't seen the result, namely the Molberg operation. As far as I can find out no operation is carried out without careful selection and also a try of orthotic devices. Have you got any experience in South Africa of this kind of surgery?

Dr SHROSBREE. Well actually we have just done two Molberg operations for the transfer of the deltoid into the triceps on two cases that had no triceps action. This splint was specifically devised for a particular case who had no pronation so if we gave him extension it wouldn't have helped him very much because he had no active pronation, he only had supination.

DR Dollfus. I must congratulate you on your collar and I think this collar is something we are looking for. The halo in the United States is somehow popular. I do not have any experience with the halo but I am still looking for a good collar and I hope that you will allow all of us here to take pictures of your collar so that we can have it devised at home by our engineers. Now, if there is no other question from the floor I would like to introduce the proferred papers and one which has been added which is a New Method of Severe Hyperextension Injuries of the Cervical Spine given by $\mathrm{Mr}$ Harris. 